\title{
Erratum zu: Können sich erneuerbare Energien langfristig auf wettbewerblich organisierten Strommärkten finanzieren?
}

Oliver Kopp • Anke Eßer-Frey · Thorsten Engelhorn

Online publiziert: 16. Mai 2013

(C) Springer Fachmedien Wiesbaden 2013

Erratum zu: Z Energiewirtsch (2012) 36:243-255

DOI 10.1007/s12398-012-0088-y

In Tab. 1 wurden einige Eingangsparameter nicht korrekt widergegeben. Hier die korrigierten Werte:

Tab. 1 Überblick über zentrale Eingangsparameter

20152020203020402050

\begin{tabular}{|c|c|c|c|c|c|c|}
\hline $\mathrm{Gas}\left[€_{2011} / \mathrm{MWh}_{\mathrm{th}}\right]$ & & 28 & 30 & 34 & 37 & 41 \\
\hline Kohle $\left[€_{2011} /\right.$ tSKE] & & 93 & 95 & 98 & 100 & 102 \\
\hline \multirow[t]{2}{*}{$\mathrm{CO}_{2}\left[€_{2011} / \mathrm{t}\right]$} & Referenzszenario & 15 & 30 & 40 & 52 & 68 \\
\hline & $\begin{array}{l}\text { Szenario Hohe } \\
\mathrm{CO}_{2} \text {-Preise }\end{array}$ & 15 & 54 & 131 & 208 & 285 \\
\hline
\end{tabular}

Die Online-Version des Originalartikels können Sie unter doi:10.1007/s12398-012-0088-y finden.

O. Kopp $(\bowtie) \cdot$ A. Eßer-Frey · T. Engelhorn MVV Energie AG, Mannheim, Germany e-mail: o.kopp@mvv.de 